\section{Female genital mutilation}

\section{Should be abolished}

EDTTOR-Is the abolition of female genital mutilation just another feminist issue? Is it racism or cultural insensitivity to stamp out this practice in Britain? Should we continue to avoid doing anything about it on the grounds that it is "a private, difficult, and sensitive" issue? Anyone who does not know the answers to these questions should take another look at the photograph of a female infant being mutilated ${ }^{1}$ because it answers all questions relating to what the correct stance of the Western world to this practice should be.

Concerted action should be taken to abolish female genital mutilation in Britain, with full judicial and government support. The French example is worth studying. ${ }^{1}$ The Royal College of Obstetricians and Gynaecologists has pioneered many initiatives in the past aimed at improving the health and welfare of women and may be best suited to coordinating activities aimed at evaluating the size of this problem and providing viable intervention strategies.

A lasting solution to this issue can, however, come only through a workable global initiative. The influence of Western-type education in stopping this practice has been documented in an indigenous population of Nigerian Igbos. ${ }^{2}$ This has been confirmed in many other reports, but it would be naive to believe that education alone is enough to eradicate the practice in every region of the world: education in this context probably acts as a marker of female emancipation and so may be a strong factor in certain parts of the world while in others its influence may be suppressed by stronger cultural factors. Furthermore, it is not realistic to wait for all women to become educated.

Contrary to J A Black and G D Debelle's assertion, ${ }^{1}$ female genital mutilation is not largely confined to Muslims, and attempts have been made to correct this misrepresentation. ${ }^{3}$ The perpetuation of this myth may provoke antagonism in the very areas where maximum cooperation is required for any global intervention to stand any chance of success. Religion has never nurtured female genital mutilation, except for that practised by the Christian Skoptozy sect in Russia, which in the past supported female genital mutilation with quotations from the Bible (Matthew xix, 12). ${ }^{4}$ Tradition is the main reason why this barbarous act still continues in parts of the developing world, and many Islamic areas do not have this custom.

Eradication of the practice in those Islamic

\section{Advice to authors}

We prefer short letters that relate to a recently published article and we are unlikely to publish letters longer than 400 words and containing over five references. Letters may be shortened. Your letters should be typed with double spacing and include a word count. All authors need to sign the letter and provide one current appointment and address. We encourage you to declare any conflict of interest. Please enclose a stamped addressed envelope if you require an acknowledgment. countries where it is still carried out may be easier than everyone thinks because religion is the dominant component of the complex mix of religion, culture, and nationalism that exists in such parts. Thus if Islamic scholars and leaders established that this practice was not required, support for it might melt away-rapidly, too, if a public stance was then taken against it by these leaders. The Western world can contribute positively to this by making quiet, unpublicised representations to these leaders: anything else migh elicit negativistic responses. In the animist and Christian parts of the developing world, education, particularly of women, will lead to the disappearance of this custom in the long term, while intensive public health campaigns will hasten this process.

GODWIN I MENIRU Clinical research fellow

London Gynaecology and Fertility Centre, London W1N $1 \mathrm{AF}$

MARYANN O MENIRU Health psychologis

Nottingham Trent University,

Nottingham NG1 4BU

UCHECHUKWU O EZEF Clinical research fellow

University Department of Obstetrics and Gynaecology,

Jessop's Hospital For Women

Sheffield S3 7RE

1 Black JA, Debelle GD. Female genital mutilation in Britain. BMF 1995;310:1590-4. (17 June.)

2 Meniru GI. Female circumcision among the Igbos of Nigeria trends. Nigerian fournal of Medicine 1991;1:55-60.

3 Meniru GI. Female genital mutilation. Br $₹$ Obstet Gynaecol 1994;101:832.

4 Mustafa AZ. Female circumcision and infibulation in the Sudan fournal of Obstetrics and Gynaecology of the British Commonwealth 1966;73:302-6.

\section{Cultural knowledge is the key to understanding}

EDrToR,-J A Black and G D Debelle's review of female genital mutilation is superficial in its treatment of the anthropological context and the complexity of the challenges facing professionals in child protection. ${ }^{2}$ Current beliefs about the function of female genital mutilation are diverse and include easier childbirth and the prevention of infant death. Focusing on female genital mutilation solely as a control on female sexuality not only misrepresents the situation but is unlikely to enable professionals to establish meaningful dialogues with the communities in questionan essential prerequisite to eradication of the practice. Many communities regard the operations performed at initiation essential, to remove the female elements of the male (the prepuce) and the male elements of the female (the clitoris). For them, in common with almost every group in which it occurs, female genital mutilation is a prerequisite for a woman to be truly female. ${ }^{3}$ There are many communities in which female genital mutilation is believed to ensure "purity," but, even in these, to regard it as an exercise in male supremacy makes sense only in a histological or anthropological context. The practice is currently maintained, and jealously guarded, by women. ${ }^{3}$

Female genital mutilation is not largely confined to Muslims but found across many ethnic groups and faiths, including Jews (Falashas) and followers of indigenous religions. ${ }^{4}$ The practice probably first arose among the southern Cushitic peoples, as it and other southern Cushitic customs are found in the descendants of these peoples and in those of other groups influenced by them. ${ }^{5}$ These peoples are scattered across the African Sahel, which coincidentally is that part of sub-Saharan Africa in which Islam later became established.

Female genital mutilation occurs in less than $30 \%$ of Yemenis but is virtually universal in Somalia. ${ }^{4}$ Professionals need accurate information about its prevalence in the communities they serve: providing a vague average of $80 \%$ is unhelpful.

There has been no comprehensive study of the epidemiology of female genital mutilation in Britain, and thus no reliable information is available on when British children are mutilated. In Africa the age at which female genital mutilation is carried out varies from birth to marriage. ${ }^{4}$ Wherever the practice is illegal I would guess that it is performed opportunistically, regardless of age. Discussions with Somalis in Cardiff support this supposition.

Black and Debelle's article details orders that can be made under the Children Act. To my knowledge, an order has been obtained because of female genital mutilation on only one occasion; this case predated the act. Female genital mutilation is unusual in that once it has been performed the child does not face continuing risk. This, together with the powers that children have under the act to refuse examination and the difficulty of establishing in a court, solely on the basis of a sibling's experience, that a child is at risk of abuse, explains some of the difficulties facing local authorities. The Children Act may have made protection of this group more problematic.

Finally, the Somali community comprises clans, not tribes. Somalia is the most ethnically homogeneous of all the countries in Africa, having only one tribe-the Somalis.

ELSPETH WEBB

Department of Child Health, Senior lecturer in child health

University of Wales College of Medicine, Cardiff CF4 4XN

1 Black JA, Debelle GD. Female genital mutilation in Britain. BMf 1995;310:1590-4. (17 June.)

Webb E, Hartley B. Female genital mutilation: a dilemma in child protection. Arch Dis Child 1994;70:441-4.

3 Ahmadu F. Rites and wrongs. Pride 1995 April/May: 43-6.

4 Hosken F. The Hosken report-genital and sexual mutilation of females. Women's International Network News 1982.

5 Fedders A, Salvadori C. Peoples and cultures of Kenya. Nairobi: Transafrica Book Distributors, 1979.

\section{Professionals should not collude with} abusive systems

EDrTor,-J A Black and G D Debelle do not go far enough in their article on female genital mutilation.' They state, "genital mutilation is a form of child abuse, though this term should not be used when discussing the procedure with families as it would be greatly resented." This suggests that the feelings of the families and doctors should be given precedence over the feelings of the child(ren) being permanently mutilated. This represents collusion with an abusive system, which, unfortunately, is not unusual when children's feelings are concerned. ${ }^{2}$

They state that "there is little point in prosecuting parents for something which has already occurred." If this principle was applied wholesale there would be no point in having a law prohibiting the act, nor would any prosecutions be brought for 
acts of sexual abuse, of which genital mutilation is a gross example.

In addition, they state that "genital mutilation differs from other forms of child abuse in that it is done with the best intentions for the future welfare of the child." This represents another collusion with the abusive system: there is no benefit to the child. The only people to benefit are the oppressors who wield their power within that particular culture.

The authors seem to dismiss the importance of resulting psychological trauma. In my research on post-traumatic stress disorder in women who had undergone obstetric or gynaecological procedures I found that women could be severely traumatised psychologically by painful, mutilating vaginal procedures that were carried out without clear consen in an unsympathetic environment. ${ }^{3}$ Obstetric and gynaecological procedures are an accepted form of medical practice in Britain that women are taugh to expect, yet women may still develop posttraumatic stress disorder as a result of their "culturally accepted" experiences.

Black and Debelle casually refer to "male circumcision" as if it is benign. It is also medically unjustifiable genital mutilation, which is sanc tioned by a culture purporting to be civilised. ${ }^{+5}$

It is time that genital mutilation was banned completely and that the medical profession faced up to its collusion in the harming of patients.

JANET MENAGE

Holbrooks Medical Centre

Coventry

1 Black JA, Debelle GD. Female genital mutilation in Britain BMF 1995;310:1590-4. (17 June.)

Miller A. Banished knowledge: facing childhood injuries. London: Virago, 1991

3 Menage J. Post-traumatic stress disorder in women who have undergone obstetric and/or gynaecological procedures. Foumal of Reproductive and Infant Psychology 1993;11:221-8.

4 De Castella $\mathrm{H}$. Prepuceplasty: an alternative to circumcision Ann R Coll Surg Engl 1994;76:257-8.

5 Wright JE. The treatment of childhood phimosis with topical steroid. Aust NZ F Surg 1994;64:327-8.

${ }_{*}^{*}$ As well as the three letters here we received five others. Two agreed with Janet Menage that male circumcision is also genital mutilation of a child without consent; another agreed with Elspeth Webb's anthropological analysis; a fourth contained an account of a 10 year old girl who bled to death after being circumcised in Egypt, where, according to the correspondent, $85 \%$ of all women are circumcised; and the fifth was a request for information, which has been passed to the Royal College of Obstetrics and Gynaecology.-EDITOR

\section{Dangers of cocaine and adrenaline paste}

\section{Exceeding the recommended dose may have serious sequelae}

EDITOR,--K E A Nicholson and J E G Rogers report serious complications associated with the use of topical cocaine with adrenaline, ${ }^{\prime}$ but they draw inappropriate conclusions about the evidence they present and fail adequately to emphasise that the recommended doses and concentrations were exceeded. ${ }^{23}$ It is perhaps not surprising that serious sequelae may occur under these circumstances.

We are surprised that Nicholson and Rogers feel able to conclude from their three cases that it was the combination of cocaine and adrenaline that is responsible for the complications they observed this is an unreasonable assumption. The randomised trial they quote showed that the addition of $1 / 1000$ adrenaline to a $10 \%$ solution of cocaine was generally associated with significantly lower plasma cocaine concentrations than were seen with cocaine alone and that the combination of the two drugs was not associated with a change in cardiovascular variables. ${ }^{4}$

The fact that this combination of the two drugs is potentially hazardous is an important message. The current recommendations in the British National Formulary ${ }^{2}$ are accepted by the British Association of Otorhinolaryngologists-Head and Neck Surgeons. There seems to be little evidence that these recommendations are inappropriate.

MARTIN BURTON Senior registrar in otolaryngology RICHARD MARKS

Barnet General Hospital, Consultant anaesthetist

Herts EN5 3DJ

1 Nicholson KEA, Rogers JEG. Cocaine and adrenaline paste: a fatal combination. BMf 1995;311:250-1. (22 July.)

BMA and Royal Pharmaceutical Society of Great Britain. British national formulary No 29. London: BMA, RPSGB, 1995.

Reynolds JEF, ed. Martindale. The extra pharmacopoeia. London: Pharmaceutical Press, 1993.

4 Bromley L, Hayward A. Cocaine absorption from the nasal mucosa. Anaesthesia 1988;43:365-8.

\section{Accurate measurement of dose and patience are important}

EdITOR,-K E A Nicholson and J E G Rogers's lesson of the week about arrhythmias associated with the use of cocaine and adrenaline paste ${ }^{1}$ is bound to fuel the controversy surrounding the use of these two drugs in sinonasal surgery. It is unclear from their report whether the overdose of cocaine was intentional or inadvertent: all three patients reported on received two to three times the maximum recommended dose of cocaine for their weight. With no evidence of similar complications when cocaine is used in recommended doses, to abandon this drug combination in all forms seems an overreaction. Recommended maximum doses surely have a purpose. Overdose of almost any anaesthetic drug will result in death; this does not result in a generalised call for withdrawal or the drug, nor should it.

The volume of cocaine paste can be measured with a $2 \mathrm{ml}$ syringe; this avoids inadvertent overdose. In at least two of the cases reported, arrhythmia occurred after nasal instruments were applied. This suggests an inadequate period between local application of the paste and the start of the operation.

We suggest the following recommendations for the use of cocaine and adrenaline paste: use less concentrated $(10 \%)$ paste; use a $2 \mathrm{ml}$ syringe to measure the volume of the paste; do not exceed the stated maximum dose per $\mathrm{kg}$; and allow adequate time for anaesthesia to occur. These steps will at least enable proper evaluation of any cardiac event.

Although we do not use cocaine and adrenaline paste, we routinely use a solution of both drugs for patients undergoing functional endoscopic sinus surgery. Over the past four years we have treated over 400 patients without adverse effects, using up to $20 \mathrm{ml}$ of $0.625 \%$ cocaine, $0.0625 \%$ ephedrine, and $1 / 20000$ adrenaline instilled into the nose with the patient in a head down, supine position for 10 minutes after general anaesthesia has been established. This works well, resulting in excellent decongestion and improved haemostasis, which render the procedure much safer.

Finally, although "nasal surgery is rarely life saving," sinus surgery may prevent the development of serious complications, such as blindness, meningitis, and the formation of intracranial abscesses. Endoscopic procedures on the sinuses require adequate visualisation so that important structures, including the dura, orbits, optic nerves, and internal carotid arteries, are not endangered. To misquote the authors: the complications of sinusitis may be life threatening in patients who are otherwise young and fit. The disadvantages of correct doses of local decongestion must be substantial to justify the increased risk that surgery without it would entail. in ear, nose, and throat ROBERT SLACK

Royal United Hospital

Consultant ear, nose, and throat surgeon

Bath BA1 3NG

1 Nicholson KEA, Rogers JEG. Cocaine and adrenaline paste: a fatal combination? BMF 1995;311:250-1. (22 July.)

\section{Combination is still widely used}

EDITOR,-The use of cocaine and adrenaline paste is a controversial issue among otolaryngologists. In 1991 the British Association of Otolaryngologists-Head and Neck Surgeons surveyed all consultant surgeons who were members and found that $63.5 \%$ used cocaine without adrenaline, $19 \cdot 5 \%$ used cocaine and adrenaline, and $17 \%$ used cocaine with and without adrenaline. ${ }^{2}$ Of the 312 who used cocaine, 76 had changed their method of using it since 1986, generally because of concern about safety. Six deaths were recorded in the report.

The British National Formulary states that "cocaine is still used in otolaryngology and is applied to the nasal mucosa in concentrations of 4 to $10 \%(40-100 \mathrm{mg} / \mathrm{ml})$. The maximum total dose recommended for application to the nasal mucosa in fit adults is a total of $1.5 \mathrm{mg} / \mathrm{kg}$, which is equivalent to a total topical dose of approximately $100 \mathrm{mg}$ for an adult male. It should be used only by those skilled in the precautions needed to minimise absorption and the consequent risk of arrhythmias. Although cocaine interacts with other drugs liable to induce arrhythmias, including adrenaline, some otolaryngologists consider that combined use of topical cocaine with topical adrenaline (in the form of a paste or a solution) improves the operative field and may possibly reduce absorption." 3

My practice is to use cocaine paste, which is given in the anaesthetic room, and then to inject the nasal mucosa with $1 / 80000$ adrenaline in the operating room at the beginning of surgery. There have been no documented problems with this method of sequential administration.

I agree with K E A Nicholson and J E G Rogers that nasal surgery is rarely life saving and that a heightened awareness of the possible complications and interactions of the drugs being given is to be encouraged.

Department of Otolaryngology,
Royal Free Hospital NHS Trust,

R W R FARRELL

Royal Free Hospital

1 Nicholson KEA, Rogers JEG. Cocaine and adrenaline paste: fatal combination? BMf 1995;311:250-1. (22 July.)

2 British Association of Otolaryngologists-Head and Neck British Association of Otolaryngologists- Head and Neck
Surgeons, Royal College of Surgeons of England. Questionnaire on the use of cocaine. BAOL Nerusletter 1991:11-3.

3 BMA and Royal Pharmaceutical Society of Great Britain. British national formulary No 29. London: BMA, RPSGB, 1995:507.

\section{Other aspects of anaesthetic technique may have added to danger}

EDITOR,-We take issue with $\mathrm{K}$ E A Nicholson and J E G Rogers's conclusions regarding use of the combination of cocaine paste with adrenaline for preparing the nose before nasal surgery.' We agree that the recommended doses should not be exceeded, but the case for removing adrenaline from the mixture has not been made.

In cases 1 and 2 both children were given premedication of oral atropine, and the endogenous catecholamine concentration would therefore have been high because of anxiety. Anaesthesia was extremely light, and halothane, which predisposes to arrhythmias when used in combination with adrenaline, was used in both cases. The papavere- 